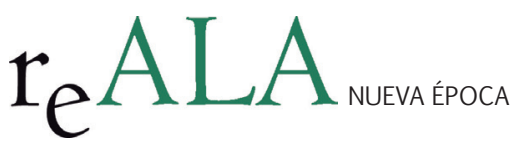

REALA, n Extraordinario, enero 2015 ISSN: 1989-8975

DOI: http://dx.doi.org/10.24965/reala.voiExtra.10223

\title{
La situación del personal al servicio de la Administración Local
}

\author{
Lorenzo Mellado Ruiz \\ Profesor Titular de Derecho Administrativo. Universidad de Almería \\ Imellado@ual.es
}

\section{Resumen}

Se analizan en este artículo los aspectos más importantes relacionados con el empleo público local derivados de la reforma del régimen local español de 2013. Sobre la base de los principios centrales de control, estabilidad presupuestaria, recuperación de las competencias estatales y limitación del personal, se estudian las nuevas previsiones sobre el personal eventual y directivo, el nuevo y detallado régimen de los funcionarios locales con habilitación de carácter nacional y las modificaciones en materia de régimen retributivo, número de altos cargos y funciones de intervención. Se ha pretendido, sobre todo, verificar el grado de cumplimiento y desarrollo de las nuevas determinaciones a un año de la entrada en vigor de la Ley.

Palabras clave

Empleo público local, funcionarios locales, control económico-financiero, función directiva, reordenación de recursos humanos

\section{The Situation of Personnel Working for Local Government}

\section{Abstract}

The aim of this paper is to deal with the most outstanding aspects that arise from the new regulation of public officials in Spain, after the 2013 Act. Mainly focused on the principles of control, budgetary stability, restoration of Goverment competences and limitation of the number of public officials, this paper analyze the new regulation of the local civil servants, specially the so called "funcionarios con habilitación de carácter nacional" and the modificantions in remuneration regime, quantity of senior staff and intervention functions. Furthermore, it is intended checking the degree of compliance and development the new determinations one year after it has been passed.

\section{Keywords}

Local public employment, local civil servants, economic and financial control, leadership role, human resources reordering. 
1. Introducción: el empleo público local a un año de la reforma. 2. Alcance de las limitaciones retributivas de los miembros de las Corporaciones Locales y del personal al servicio de las entidades locales. 3. Limitación del número de cargos públicos en régimen de dedicación exclusiva y del personal eventual. 4. La nueva regulación de los funcionarios de Administración local con habilitación de carácter nacional: ¿recentralización o eficiencia?. 4.1. Una premisa previa: el sistema de fuentes del régimen de los funcionarios locales y la (ampliada) reserva de funciones de autoridad a los funcionarios de carrera. 4.2. Innovaciones del régimen de los funcionarios de administración local con habilitación de carácter nacional. 5. Control económico-financiero de la actividad local y fortalecimiento de las funciones de intervención. 6. El personal directivo de la Administración local. 7. Otras previsiones con posibles efectos indirectos sobre el empleo público local. 8. Bibliografía

\section{INTRODUCCIÓN: EL EMPLEO PÚBLICO LOCAL A UN AÑO DE LA REFORMA}

Cuando se cumple el primer año de la entrada en vigor de la Ley 27/2013, de 27 de diciembre, de Racionalización y Sostenibilidad de la Administración Local (en adelante LRSAL), parece oportuno plantear un análisis fundamentalmente aplicativo y crítico sobre la consecución o no, o al menos la puesta en marcha de medidas enderezadas a ello, de los objetivos y finalidades fundamentales buscadas por el legislador estatal con la reforma, sobre todo, como es el caso, de las medidas, quizás las más concretas y directas, de reorganización y control de alguno de los elementos del sistema de empleo público local.

Cabe recordar que el tercer gran objetivo de la LRSAL era, junto con la racionalización del modelo competencial y de la propia estructura organizativa del sector público local, la "garantía de un control financiero y presupuestario más riguroso", finalidad que conecta claramente con los postulados transversales de la reforma de consolidación de los principios de estabilidad presupuestaria y reducción del déficit público en el ámbito específicamente local. Prácticamente todas las medidas puestas en marcha en materia de empleo público local obedecen, en primera instancia, a estas motivaciones, más económico-presupuestarias que de efectiva modernización y racionalización de las escalas políticas, directivas y funcionariales de las entidades locales: desde el fortalecimiento de la figura del Interventor local y de los funcionarios con habilitación de carácter nacional, a fin de dotarlos de mayor imparcialidad y garantizar dicho control financiero y presupuestario -mediante su "recuperación estatal", como veremos-, hasta el intento de relativa "profesionalización” del personal directivo, pasando por las medidas más específicas y directas de limitación retributiva de los miembros de las corporaciones locales o del número de empleados eventuales de las mismas.

Analizamos en este artículo dichas previsiones, y sobre todo su desarrollo y aplicación en este primer año de vida tras la reforma, teniendo en cuenta además que el impacto de la misma sobre los recursos humanos de las entidades locales no va a derivar sólo de las medidas directas anticipadas, sino también, de forma mediata, de la progresiva implantación de otras determinaciones de la LRSAL (posible fusión de municipios, degradación de rango de las entidades locales menores, incumplimiento de los planes económico-financieros de rescate, reordenación del sector público instrumental local, etc.) con evidente repercusión sobre los mismos.

En cualquier caso es evidente, para acabar este primer epígrafe introductorio, que la reforma no pretende -ni va a suponer, lógicamente- una reorganización sostenible global y en clave de innovación de las estructuras y del régimen del empleo público local (entre otras cuestiones por las propias limitaciones competenciales de la legislación básica estatal). La LRSAL, por su origen y cobertura competencial, tiene una finalidad y unos objetivos más limitados (y por ello la reforma no se limita a la modificación de aspectos específicos del régimen estatutario de los empleados públicos locales, sino que también afecta a la situación de cargos públicos electos o al régimen del personal directivo, que no se considera empleado público en la legislación básica estatal de empleo público). Pero quizás al control, a la consecución del equilibrio presupuestario general y a la contención del gasto (supérfluo o injustificado), también necesarios, habría que añadir, desde las propias premisas de la diversidad territorial y organizativa del nivel local de gobierno y de la esencialidad operativa del "factor humano" en la materialización de las políticas y servicios públicos, y en definitiva, en la realización del principio clave de "autonomía local”, nuevas y urgentes medidas -también de carácter básico o principial- de redimensionamiento y versatilidad de las estructuras y relaciones organizacionales en el ámbito local, racionalizando y simplificando el propio funcionamiento de los entes locales, con mejora en la calidad de los propios procesos de gestión, incorporación efectiva de las nuevas tecnologías de la información, mejora de los sistemas de rendimiento, evaluación y promoción internas, etc. 


\section{ALCANCE DE LAS LIMITACIONES RETRIBUTIVAS DE LOS MIEMBROS DE LAS CORPORACIONES LOCALES Y DEL PERSONAL AL SERVICIO DE LAS ENTIDADES LOCALES}

Según el nuevo art. 75 bis LRBRL, los miembros de las Corporaciones Locales serán retribuidos por el ejercicio de su cargo según las determinaciones contenidas genéricamente en el art. 75 LRBRL. Pero además, los Presupuestos Generales del Estado determinarán, anualmente, el límite o techo máximo total que pueden percibir por todos los conceptos retributivos y asistencias, excluidos los trienios a los que en su caso tengan derecho aquellos funcionarios de carrera que se encuentren en situación de servicios especiales, atendiendo entre otros criterios -que no se especifican en la Ley- a la naturaleza de la Corporación Local y a su población, según la propia tabla contenida en este artículo. Realmente hasta ahora no existía un límite total de porcentaje para las retribuciones de los miembros de las Corporaciones locales, en relación con los presupuestos de las respectivas entidades, a cuya necesidad parece apuntar no obstante el mantenido art. 75.5 LRBRL1.

En el caso de los Presidentes de las Diputaciones Provinciales o entidades equivalentes, su límite máximo por todos los conceptos retributivos y asistencias será igual a la retribución del tramo correspondiente al Alcalde o Presidente de la Corporación Municipal más poblada de su provincia.

La medida viene informada, obviamente, por los principios de control y fiscalización de los márgenes retributivos de los miembros electos de las entidades locales, y de transparencia pública sobre su dimensión².

En este sentido, el RD-Ley $1 / 2014$, de 24 de enero, de reforma en materia de infraestructuras y transporte y otras medidas económicas ha venido a introducir, como desarrollo de estas previsiones, una nueva D. A. $90^{\mathrm{a}}$ en la Ley 22/2013, de 23 de diciembre, de Presupuestos Generales del Estado para el año 2014, para incorporar el límite máximo total a percibir por los miembros de las Corporaciones locales por todos los conceptos retributivos y asistencias en este ejercicio ${ }^{3}$.

Los miembros de Corporaciones locales de población inferior a 1.000 habitantes no tendrán, en cualquier caso, dedicación exclusiva: excepcionalmente, podrán desempeñar sus cargos con dedicación parcial, percibiendo sus retribuciones igualmente dentro de los límites máximos señalados al efecto en la Ley de Presupuestos correspondiente.

Sólo los miembros de la Corporación que no tengan dedicación exclusiva ni dedicación parcial recibirán asistencias por la concurrencia efectiva a las sesiones de los órganos colegiados de la Corporación de que formen parte, en la cuantía señalada por el Pleno de la misma.

Más discutibles son, sin embargo, las limitaciones retributivas establecidas en relación ya con cualesquiera empleados públicos de las entidades locales (tanto de carácter funcionarial como laboral). En este caso, las Leyes de Presupuestos podrán (de forma, pues, potestativa) establecer un límite máximo y mínimo total que por todos los conceptos retributivos (incluyendo por tanto, dentro de la indefinición actual de las retribuciones complementarias establecida por el art. 24 EBEP, productividad y gratificaciones) pueda percibir el personal al servicio de las Entidades Locales y entidades de ellas dependientes en función del grupo profesional de los funcionarios públicos o equivalente del personal laboral. Aunque es indiscutible la competencia estatal para la adopción de este tipo de medidas de uniformización (lo que no significa que siempre sean defendibles, sobre todo desde la perspectiva específica del impacto de las mismas sobre las propias facultades de autoorganización y autonomía de gestión de las propias entidades locales ${ }^{4}$ ), sobre todo desde la óptica del control financieropresupuestario y de sostenibilidad económica de las entidades locales, las mismas atienden a una perspectiva de uniformización y rigidez quizás incompatible con la diversidad de situaciones, y la propia versatilidad demandante de un servicio público efectivo, de la realidad local, pudiendo suponer, además, una discriminación injustificada respecto de otros Cuerpos o Escalas funcionariales del resto de las Administraciones Públicas ${ }^{5}$. Además, esta fijación estatal de los límites presupuestarios máximos y mínimos de los empleados públicos locales puede estar

\footnotetext{
1 Guía práctica sobre la Ley de Racionalización y Sostenibilidad de la Administración Local, Fundación Democracia y Gobierno Local (2014).

2 Hay que recordar que, también como medida de apertura y recuperación de la confianza, desde la Ley 19/2013, de 9 de diciembre, de transparencia, acceso a la información y buen gobierno, los miembros de las Corporaciones locales tienen la obligación de hacer públicas sus declaraciones anuales de bienes y actividades, en los propios términos previstos en la LRBRL, aunque la propia Ley, matizando esta exigencia -y haciéndola coincidir curiosamente casi con el fin de la actual legislatura estatal- concede un plazo de adaptación a las medidas, determinaciones y obligaciones que estipula, para las entidades autonómicas y locales, de, nada más y nada menos, dos años (D. F. $9^{a}$ ).

3 Como se sabe, los cargos representativos de las entidades locales no se insertan, realmente, en las limitaciones retributivas en materia de gastos de personal para los empleados públicos contenidas en el art. 20 de la LPGE para 2014, sino en las del art. 22 (altos cargos), dentro, además, de la conocida prohibición genérica de incremento de tales retribuciones respecto de las vigentes a 31 de diciembre de 2013.

4 Vide, así, FORCADELL I ESTELLER (2014: 72).

5 SERRANO PASCUAL (2014): 609.
} 
establecida no sólo en función -de forma más objetiva- del grupo profesional, sino, mucho más ambiguamente, "de otros factores que se puedan determinar en las Leyes de Presupuestos Generales del Estado de cada año".

Para el personal laboral sí se establece, además, en el nuevo art. 103 bis LRBRL, que las Corporaciones locales aprobarán anualmente la masa salarial del mismo en relación al conjunto de su sector público, respetando, como hasta ahora, los límites y las condiciones que se establezcan con carácter básico en las correspondientes Leyes de Presupuestos Generales del Estado (información que ha de ser publicada en la sede electrónica de la entidad y en el boletín oficial provincial o autonómico correspondiente $)^{7}$, siendo destacable la inclusión dentro de su radio de aplicación, como medida de control y transparencia ${ }^{8}$, no sólo de los organismos, entidades públicas empresariales y demás entes públicos, sino también, y de forma expresa, de las sociedades mercantiles locales dependientes, consorcios y fundaciones cuando: i) se constituyan con una aportación pública mayoritaria, directa o indirecta o ii) su patrimonio fundacional, con un carácter de permanencia, esté formado en más de un 50\% por bienes o derechos aportados o cedidos por las entidades matrices reseñadas 9 .

La Ley concede, no obstante, cierto margen de maniobra operativa en la interiorización de las limitaciones contenidas en los arts. 75 bis y ter LRBRL. Según la D. T. $10^{\text {a }}$ LRSAL, a las entidades locales que cumplan los objetivos de estabilidad presupuestaria y deuda pública, y además su período medio de pago a proveedores no supere en más de 30 días el plazo máximo previsto en la normativa de morosidad, no se les aplicarán, con carácter excepcional, dichos límites, aunque en ningún caso el cumplimiento de estos requisitos habilitará para el incremento del número total de puestos de trabajo de personal eventual o cargos públicos con dedicación exclusiva respecto a la situación a 31 de diciembre de 2012. En relación a esta D. T. pueden hacerse las siguientes consideraciones:

- Queda claro que las limitaciones retributivas y del número de cargos públicos con dedicación exclusiva no obedecen a un fin de racionalización o adecuación funcional de las estructuras locales y su personal (electivo o profesional) a la propia capacidad o necesidad de gestión o a las características propias de la población correspondiente, sino al ahorro y contención en el gasto público: a pesar de la posible inadecuación operativa el número de cargos públicos (o de la innecesariedad real del número de personal eventual), si existe estabilidad presupuestaria, no se aplican los nuevos límites legales;

- Incluso es posible que entidades que incumplen la Ley (siempre que la media del incumplimiento de pago a proveedores no supere en más de 30 días el plazo máximo, y por tanto, obligatorio), también queden excepcionadas de los mismos;

- No se aclaran los términos o el alcance de la "excepcionalidad” de esta medida de gracia (¿cuándo será la situación excepcional y cuando no?, ¿quién declara la excepcionalidad del incumplimiento de una disposición legal genérica?, etc. $)^{10}$, lo cual puede generar inseguridad jurídica y diferencias en el tratamiento jurídico de las entidades locales.

- Y, finalmente, es posible, incluso, que la excepción se aplique a entidades locales que cumplan con dichos requisitos en el momento de la entrada en vigor de la LRSAL, manteniéndose su aplicación hasta el 30 de junio de 2015, siempre que se sigan cumpliendo, lo cual, por lo demás, parece obvio, pero no se entiende que si se siguen

$6 \quad$ Como se ha destacado, en este sentido, la LRSAL parece incorporar claramente un salto cualitativo de gran importancia sobre el régimen retributivo del personal al servicio de la Administración local, que no augura nada bueno para el conjunto de los empleados públicos locales y tampoco para las competencias municipales de ordenación de sus recursos humanos: "a falta de conocer su concreta puesta en práctica, el precepto por sí mismo presenta serias dudas de constitucionalidad, tanto por violación del principio de autonomía local al cercenar la potestad de autoorganización de las corporaciones locales como por su colisión con el derecho constitucional de negociación colectiva reconocido tanto al personal funcionario como al laboral" (FONDEVILA ANTOLíN: 467).

7 Para el año 2014, la Ley 22/2013, de 23 de diciembre, de Presupuestos Generales del Estado (art. 20.4) ya había previsto, antes de la LRSAL de hecho, la congelación, con algunas excepciones, de la masa salarial del personal laboral.

8 Realmente, el sector público local contemplado en el art. 103 bis LRBRL excede de las entidades que integran el Presupuesto General de la Entidad Local, definido en el art. 164 del RD-Legislativo 2/2004, de 5 de marzo, por el que se aprueba el Texto Refundido de la Ley Reguladora de las Haciendas Locales, como se estudia en DíEZ QUESADA Y GONZÁLEZ-HABA GUISADO (2014).

9 Sin embargo, y a falta de desarrollo específico de estas previsiones, quizás hubiera sido conveniente establecer directamente obligaciones de control y publicidad pero con un mínimo y necesario desglose, para conocer, efectivamente, el coste presupuestario de los distintos tipos de empleados laborales, en tanto que muchos de los acuerdos municipales adoptados hasta la fecha para el cumplimiento de esta obligación no entran en detalle en la pormenorización de tal distribución, con referencias incluso genéricas a las partidas vinculadas "a otro personal laboral”. Por tomar sólo tres ejemplos, el anuncio del Ayuntamiento de Campo de Criptana (Ciudad Real) de 17 de marzo de 2014 sólo informa del importe total de la masa salarial; el del Ayuntamiento de Sabiñánigo (Huesca), de 1 de abril de 2014 , apenas discrimina mínimamente entre personal laboral fijo y personal laboral temporal; mientas que el de Alcudia (Baleares), desglosa el importe detalladamente por tipos de empleados y entidades dependientes o vinculadas al mismo (Boletín Oficial de las Islas Baleares de 18 de septiembre de 2014 ).

10 El apartado segundo de esta D. T. $2^{\text {a }}$ sólo establece que el cumplimiento de los requisitos previstos (que a mi juicio no predetermina necesariamente la habilitación ulterior de la exención) será verificado por el Ministerio de Hacienda y Administraciones Públicas, que, en virtud de la información comunicada por las Entidades Locales, publicará una lista de las Entidades “cumplidoras”. 
cumpliendo los requisitos legales, una determinación legal no pueda seguir desplegando efectos después de dicha fecha.

\section{LIMITACIÓN DEL NÚMERO DE CARGOS PÚBLICOS EN RÉGIMEN DE DEDICACIÓN EXCLUSIVA Y DEL PERSONAL EVENTUAL}

De conformidad con lo establecido en el art. 75 LRBRL, la prestación de servicios en los Ayuntamientos en régimen de dedicación exclusiva por parte de sus miembros deberá ajustarse, ahora, y en todo caso, a los límites que se esquematizan en el nuevo art. 75 ter LRBRL. Las limitaciones se establecen en función de la población municipal, desde aquellos Ayuntamientos de municipios de menos de 1000 habitantes donde no puede haber miembros en dedicación exclusiva hasta aquellos con población comprendida entre 700.001 y 1.000.000 habitantes, donde los miembros que podrán prestar sus servicios en régimen de dedicación exclusiva no podrá exceder de 25 (con la excepción de los Ayuntamientos de Madrid y Barcelona, cuyos límites son 45 y 32, respectivamente). Como en el caso de los límites retributivos, el número máximo de miembros que podrán prestar sus servicios en régimen de dedicación exclusiva en las Diputaciones Provinciales será el mismo que el del tramo correspondiente a la Corporación del municipio más poblado de su provincia.En relación al personal eventual local, el nuevo art. 104 bis LRBRL establece, siguiendo la misma ecuación de correspondencia con la población local, una serie de límites y directrices para la dotación de puestos de trabajo cuya cobertura corresponda al mismo. En este caso, las posibilidades varían entre los municipios entre 2000 y 50000 habitantes, que excepcionalmente podrán contar con un puesto de trabajo cuya cobertura corresponda a personal eventual -y cuando no haya miembros de la Corporación local con dedicación exclusiva- y los Municipios con población superior a 500.000 habitantes, que podrán incluir en sus plantillas puestos de trabajo de personal eventual por un número que no podrán exceder al $0,7 \%$ del número total de puestos de trabajo de la plantilla correspondiente, considerando a estos efectos los entes que tengan la consideración de Administración pública en el marco del SEC ${ }^{11}$.

Parece acertada, desde su propia y ambivalente naturaleza jurídica, y a su través, por las reiteradas críticas que han recibido los denominados "falsos empleados públicos" "12 la limitación del número de empleados eventuales en las Administraciones locales ${ }^{13}$. En el EBEP no existe, con carácter básico y uniforme, tal limitación (y por ello mismo no parece suficiente un control limitado, exclusivamente, al ámbito local). El art. 12.2 EBEP remitía directa y ambiguamente a las (por ahora, en su mayoría, inexistentes) leyes autonómicas de desarrollo, la determinación de los órganos de gobierno que podrían disponer de este tipo de personal, pero, una vez autorizado, el complemento a tal reenvío era la "deslegalización” expresa del establecimiento de su número máximo (a fijar, por sí mismos, por los respectivos órganos de gobierno), con el matiz eso sí, pero tampoco concretado, de que dicho número y sus condiciones retributivas serían públicas. Pero el nuevo art. 104 bis LRBRL tampoco puede interpretarse de manera automática: el número máximo de puestos de trabajo a cubrir por personal eventual no debería ser el "aprobado" por la entidad como norma general, sino el derivado de la evaluación integrada de todos los factores concurrentes susceptibles de permitir una evaluación "adecuada" de su necesidad, proporcionalidad y funciones reales. Frente a la ambigüedad del EBEP -que pese a la carencia de funciones activas, incluye a este personal dentro de la categoría de empleados públicos-, al menos la LRSAL lleva a cabo una cierta limitación de los órganos y destinos de adscripción de este personal: como regla general, el personal eventual tendrá que asignarse -y preverse en los instrumentos de ordenación correspondiente- siempre a los servicios generales de la entidad (aunque no se aclara realmente cuáles sean éstos) y sólo excepcionalmente, con carácter funcional, a otros servicios o departamentos de la estructura propia de la misma, si así lo reflejase además expresamente su reglamento orgánico ${ }^{14}$.

11 En el caso de las Diputaciones Provinciales, el número de puestos de trabajo cuya cobertura corresponda a personal eventual será el mismo que el del tramo correspondiente a la Corporación del Municipio más poblado de la Provincia, mientras que en el resto de entidades locales y sus organismos y entidades dependientes se prohíbe directamente la posibilidad de prever puestos de trabajo en plantilla a cubrir mediante personal de confianza política y asesoramiento especial.

12 Vide FERNÁNDEZ RAMOS (2013).

13 Vide, en este sentido, CEBRIÁN ABELLÁN (2014: 801).

14 Así se desarrolla, por ejemplo, en el Decreto de 13 de mayo de 2014, de la Delegación del Área de Gobierno de Economía, Hacienda y Administración Pública del Ayuntamiento de Madrid, donde se establecen las distintas denominaciones y tipologías de puestos de trabajo de personal eventual del mismo, así como los asignados a los grupos políticos y a la Presidencia del Pleno, con una curiosa determinación orgánica, sin embargo, sobre los puestos de trabajo reservados para ser cubiertos "indistintamente" por personal eventual o por personal funcionario. En principio, los puestos de trabajo ocupados por personal eventual son puestos no reservados a funcionarios de carrera, por lo que el adverbio entrecomillado no puede entenderse en un sentido pleno, es decir, habilitante de una ocupación indiferente entre ambos tipos de empleados públicos. Es evidente que un puesto de eventual lo puede ocupar tal empleado o un funcionario de carrera, pero no al revés. El EBEP, lejos de aclarar esta cuestión, la dejó aún más abierta, desde la compleja e indeterminada aproximación funcional entre ambas categorías: "Al personal eventual le será aplicable, en lo que sea adecuada a la naturaleza de su condición, el régimen general de los funcionarios de carrera" (y parece evidente la lejanía de ambas figuras en cuanto a su "naturaleza”, precisamente), pero se trata de una cuestión conflictiva, sobre todo en el caso de la ocupación de puestos directivos, y sobre la que, por ejemplo, alguna jurisprudencia reciente ha tenido oportunidad de pronunciarse en términos categóricos: dice la STSJ de Castilla-La Mancha de 29 de marzo de 2012, rec. 595/2011, que “la clasificación de un puesto de trabajo para ser desempeñado, indistintamente, por cualquier clase de personal carece del más mínimo encaje jurídico en nuestro 
En cualquier caso, y como medida adicional de transparencia, las Corporaciones locales deberán publicar semestralmente en su sede electrónica y en el boletín oficial de la provincia, o, en su caso de la Comunidad Autónoma uniprovincial, el número de los puestos de trabajo reservados (aunque realmente en el EBEP no se habla de la posibilidad de tal "reserva") a personal eventual, debiendo el Presidente de la entidad informar al Pleno con carácter trimestral del cumplimiento de estas nuevas obligaciones y límites recogidos ahora de forma básica en la LRBRL.

Esta regla tiene, no obstante, la misma excepción ya apuntada de la D. T. 10 $10^{\text {a }}$ LRSAL: si se cumplen las condiciones establecidas en la misma, no se aplicarán estos límites hasta el 30 de junio de 2015. La uniformidad del término contrasta, como ya hemos apuntado, con una realidad necesariamente singular y específica, en su aplicación sobre todo a la posible existencia de personal de mero asesoramiento o confianza política, a lo que hay que adicionar la monocromática visión "economicista" de la Ley -en la aplicación o en la exención de sus determinaciones-: : es que la crisis de legitimidad y credibilidad de las Administraciones Públicas es sólo una crisis de insostenibilidad económico-financiera? Parece evidente que los problemas de confianza en las instituciones públicas vinculados a alguna de las medidas ahora regulada (excesivo número de personal eventual, opacidad en cuanto a su régimen jurídico y retribuciones, alcance de su responsabilidad, etc.), no dependen tanto de la capacidad financiera y presupuestaria de los municipios como de la efectiva racionalización del sistema de recursos humanos y la articulación congruente del personal electo -y sus retribuciones- en función precisamente de la mejor satisfacción de las necesidades colectivas ${ }^{15}$. Y es que, como se ha apuntado antes -en relación a los límites retributivos y a la existencia de cargos públicos con dedicación exclusiva- la redacción de la D. T. 10ª LRSAL no parece zanjar la cuestión adecuadamente. La "inaplicación" transitoria de tales limitaciones depende del cumplimiento de unos requisitos que ha de "verificar" (y publicar posteriormente), a la vista de la información elevada por los propios Ayuntamientos, el MHAP, pero, ¿en base a qué criterios se determina la excepcionalidad de la medida?, y, sobre todo, ¿quién es la Administración competente para tomar la decisión final sobre su aplicación o no? No parece que "verificar" sea lo mismo que "autorizar", con lo que, tras el control superior (que no se expresa que será "vinculante"), quien decide (o "autodecide") sobre la aplicación de una disposición básica contenida en una normativa estatal será la propia entidad local afectada, aunque de nuevo el apartado $3^{\circ}$ de dicha Disposición vuelve a complicar su entendimiento: en él se dice que la excepción reseñada "podrá aplicarse" (¿por quién? ¿con qué alcance?) siempre que -se completa la inicial mención temporal del párrafo primero- el cumplimiento de los requisitos establecidos se acredite no sólo a la entrada en vigor de la LRSAL, sino hasta -al menos- el 30 de junio de 2015.

\section{LA NUEVA REGULACIÓN DE LOS FUNCIONARIOS DE ADMINISTRACIÓN LOCAL CON HABILITACIÓN DE CARÁCTER NACIONAL: ¿RECENTRALIZACIÓN O EFICIENCIA?}

\subsection{Una premisa previa: el sistema de fuentes del régimen de los funcionarios locales y la (ampliada) reserva de funciones de autoridad a los funcionarios de carrera}

El art. 92 LRBRL, suprimido en su día por la D. D. única e) EBEP, recupera ahora la regulación genérica de los funcionarios al servicio de la Administración local, asumiendo en línea de principio la regla general de la preferencia del régimen funcionarial -sobre el laboral- de los puestos de trabajo en la Administración local y sus Organismos Autónomos. Acogiéndose la línea jurisprudencial iniciada con la STC 99/1987, de 11 de junio, sobre nuestro "sistema dual" de empleo público, no se proclama, sin embargo, una regla estricta, puesto que la ocupación de los puestos por personal funcionario será "con carácter general", no exclusivo (art. 92.2 LRBRL), pero al menos sí se positiviza una opción ausente por ahora como determinación básica en el texto del EBEP. Esto supone, por otro lado, que las Comunidades Autónomas no podrían ya regular (libremente) esta cuestión -invocando sus anteriores y amplias competencias de desarrollo en materia de función pública- para sus respectivas entidades locales, desde la nueva opción estatal básica de recuperación de las competencias sobre función pública local, pero también la más que

sistema de función pública, y sólo puede ser calificado de extravagancia".

15 Hay que señalar además, en este punto, que se vincula la exención al cumplimiento no sólo de la normativa de estabilidad presupuestaria (de la que la LRSAL es, de hecho, desarrollo directo), sino también de la de control de la morosidad en el pago a contratistas, que ni es igual -una cosa es la deuda financiera y otra distinta la deuda comercial ordinaria, aunque, como se sabe, pueden asimilarse ahora a través de los mecanismos de facilitación de pago a proveedores- ni puede recibir seguramente, como aquí, un tratamiento homogéneo como parámetros económicos, además, para la exención de medidas, propios de otro ámbito, en materia de personal y régimen de los cargos públicos locales-. La LRSAL utiliza la normativa de morosidad comercial como condicionante decisivo en materia de organización, al margen, quizás, como en otros aspectos de la reforma, de su falta de previsión y contenido en la Ley Orgánica 2/2012, de 27 de abril, de Estabilidad Presupuestaria y Sostenibilidad Financiera (LOEPSF), y de su diferente naturaleza normativa, en una posible "extralimitación positiva" por confusión funcional de ámbitos normativos. 
posible aparición de conflictos normativos interterritoriales en relación a las Comunidades con legislación propia ya sobre función pública local en desarrollo del EBEP.

\section{Sí es necesario resaltar, sin embargo, la confirmación de que:}

Los funcionarios al servicio de la Administración local (es decir, tanto funcionarios propios como ajenos con servicio en ella) se rigen primero, por la propia LRBRL y, en lo no previsto, por el EBEP y la restante legislación estatal en materia de función pública, así como por la legislación de complemento y desarrollo autonómicos correspondiente. Se recupera, así, el tradicional orden de prelación de fuentes a favor de las normas de función pública recogidas en la propia legislación básica de régimen local sobre las de la legislación básica general de empleo o función pública, matizándose a la vez -discutiblemente, a pesar de la "especial posición ordinamental" en nuestro ordenamiento de la LRBRL- el propio modelo básico de fuentes contenido en el art. 3.1 EBEP ${ }^{16}$.;

- Y que corresponde exclusivamente a dichos funcionarios de carrera: i) el ejercicio de las funciones que impliquen la participación directa o indirecta en el ejercicio de las potestades públicas o en la salvaguardia de los intereses generales y ii) las que impliquen ejercicio de autoridad (p. e. policía local) y, en general, aquellas que en desarrollo de la LRBRL se reserven a los funcionarios para la mejor garantía de la objetividad, imparcialidad e independencia en el ejercicio de su función (art. 92.3 LRBRL). Se amplia, así, la reserva legal de funciones de carácter mínimo contenida en el art. 9.2 EBEP17, hasta el punto, es posible, de habilitar una factible "deslegalización" funcional en tal delimitación, aún desde el loable -aunque muy indeterminado en su configuración positiva- objetivo de reforzar la imparcialidad y profesionalidad de determinadas funciones públicas a desarrollar en el ámbito local (cabría pensar, singularmente, en el propio cuerpo de funcionarios de habilitación de carácter nacional) ${ }^{18}$.

\subsection{Innovaciones del régimen de los funcionarios de administración local con habilitación de carácter nacional}

Desde la pretensión de fortalecimiento y privilegio del estatuto funcionarial y de desarrollo de su proyección al ámbito local, y desde la propia filosofía de "intervención y control" de la LRSAL, se explica la inclusión demandada desde hace tiempo por algunos sectores- del régimen de los -ahora de nuevo- denominados "funcionarios de administración local con habilitación de carácter nacional" dentro de la normativa básica de régimen local, derogándose completa y correlativamente la D. A. $2^{\mathrm{a}}$ y la D. T. $7^{\mathrm{a}}$ EBEP (D. D. única LRSAL). El nuevo art. 92 bis LRBRL retoma la regulación básica estatal, al margen de la normativa específica sobre empleo público, de este cuerpo estatal, comenzando por recordar que son funciones públicas necesarias, y como ha señalado en diferentes ocasiones el TC de relevancia constitucional, cuyo cumplimiento queda reservado a dichos funcionarios de administración local con habilitación nacional, las siguientes:

16 Sobre los problemas derivados del orden de prelación de fuentes y de la concurrencia de títulos competenciales en materia de régimen local y de régimen de la función pública, con sus lógicas repercusiones en orden a habilitar una mayor o menor participación "normativa" autonómica en esta materia, puede verse en profundidad FONDEVILA ANTOLín (2014: 434 y ss.). Como sintetiza el autor: " $a$ diferencia de la situación anterior, en estos momentos la legislación estatal básica con carácter especifico sobre la función pública local, en concreto, la LRBRL resulta legalmente prevalente sobre las previsiones del EBEP, es decir, volvemos al criterio de la lex specialis y su preferencia sobre la lex generalis. Lo anterior supone que esa preeminencia de la legislación básica estatal va a generar inmediatas consecuencias sobre los ámbitos competenciales de las Comunidades Autónomas, ya que éstas carecerán, en principio, de competencias para proceder a desarrollar de forma integral un «Estatuto de la Función Pública Local» para las entidades locales de su territorio, pues nada puede impedir al legislador estatal ampliar los contenidos materiales básicos que afecten al estatuto de los funcionarios públicos locales, en ejercicio de su competencia básica sobre régimen local y función pública, reconocida por el art. 149.1.18 CE" (pág. 443). También las consideraciones de CANTERO MARTínEZ (2014: 648 y ss.), para quién "la preferencia absoluta por la legislación estatal" derivada de la LRSAL "podría tener sentido en la regulación de algunos aspectos básicos del régimen de estos funcionarios pero que, a día de hoy, concuerda poco con el nivel de descentralización política en nuestro país" (pág. 651). Por el contrario, DOMINGO ZABALLOS (2014: 642), entiende que "la prevalencia de lo dispuesto en una ley sobre la otra deriva de ser la LRBRL una Ley estatal ordinaria modificada (obviamente por otra ley ordinaria -no otra cosa es la Ley 27/2013-), conteniendo preceptos básicos y posterior al EBEP, igualmente ley ordinaria con todos sus preceptos básicos".

17 "Con ello se podrá poner coto, por fin, a la huída del derecho administrativo, a través de unas plantillas sobredimensionadas de personal laboral, en detrimento del personal funcionario, cuyo sistema de selección ha adolecido en muchas ocasiones de una falta de acomodación a los principios constitucionales de mérito y capacidad, y del respeto, en suma, a la igualdad de oportunidades, así como de cumplimiento de la necesaria publicidad de la convocatoria, según ha sucedido en numerosas entidades locales" (SERRANO PASCUAL: 592).

18 Es evidente, además, que esta "reserva funcional funcionarial" -a favor de funcionarios de carrera que posean, además, nacionalidad española- se encuentra plagada de conceptos jurídicos indeterminados que habrá que ponderar adecuadamente para no dejar vacía de contenido la dualidad reconocida constitucionalmente de nuestro sistema de empleo público. Ni cabe una masiva e incondicionada "laboralización" - con huída paralela del Derecho Administrativo- del mismo ni es posible una interpretación estricta (con atención preferente al "ejercicio indirecto de potestades" o a la plasmación de "funciones de autoridad") de tal reserva, que llevaría a entender que cualquier función administrativa tiene por objeto -lógicamente- la salvaguardia o protección del interés. La participación en el ejercicio de "potestades públicas" y la protección de los "intereses generales" ha de reconducirse, funcionalmente, al desempeño estricto de potestades activas (con emanación de actos administrativos) fruto del ejercicio de funciones exorbitantes. 
- La de Secretaría, comprensiva de la fe pública y el asesoramiento legal preceptivo; y

- El control y la fiscalización interna de la gestión económico-financiera y presupuestaria y la contabilidad, tesorería y recaudación.

La LRSAL pretende, claramente, reforzar los mecanismos e instrumentos de control económico-presupuestario de los entes locales, incrementando las funciones propias de Intervención (no hay sin embargo curiosamente un posicionamiento en tal sentido, de carácter semejante, en lo relativo al "control jurídico" de la actividad local, es decir a la específica "función de secretaría"19). En este sentido, una de las nuevas "competencias propias" y "necesarias" de las Diputaciones Provinciales es la asistencia y cooperación jurídica, económica y técnica a los Municipios, especialmente los de menor capacidad económica y de gestión, garantizando en todo caso en los de menos de 1000 habitantes la prestación de estas funciones de secretaría e intervención (art. 36.1b) LRBRL), y genéricamente, el desempeño de las "funciones públicas necesarias en los Ayuntamientos", junto con el apoyo en la selección y formación de su personal (art. 36.2.c) LRBRL), en principio, y obviamente, competencias propias de cada corporación (art. 100.1 LRBRL).

Al margen de la "recuperación" formal de estos funcionarios por la legislación local, y con las modificaciones específicas que se introducen en ella, realmente el cambio fundamental que subyace a su nueva regulación básica, pues no existen pronunciamientos expresos en este sentido, es el "rescate" estatal de su ordenación material -al menos de sus aspectos más importantes-, desde la propia dialéctica inherente a la reforma entre eficacia en el control de la actividad local e incremento de las facultades estatales de intervención. La LRSAL parte del confesado presupuesto de que para reforzar su independencia con respecto a las entidades locales en las que prestan sus servicios, ha de corresponder al Estado - de nuevo, tras el paréntesis del EBEP-su selección, formación y habilitación, así como la potestad sancionadora en los casos de las infracciones más graves. Pero una cosa es la desarticulación del sistema provocada por una legislación de mínimos y sometida -por ello mismo- a las tensiones político-territoriales (D. A. $2^{\mathrm{a}}$ EBEP), y otra la identificación apriorística entre "recentralización" y "aumento de la eficacia". Su objetividad e imparcialidad respecto al ámbito propiamente local de gobierno, en tanto cuerpo estatal propio, no depende tanto de la escala territorial de dependencia como de la adecuación y congruencia de las medidas integrantes de su estatuto jurídico. Por ello lo importante será verificar que, aparte de la transferencia competencial a la Administración General del Estado, los cambios concretos en la regulación de esta Escala sean los adecuados, y coadyuven realmente a la racionalización de un modelo de ordenación hasta ahora asimétrico y descoordinado (cuando no manipulado a través del “juego" de la baremación de las especialidades autonómicas o locales), por ejemplo en lo relativo a la regularidad de las convocatorias de acceso o de promoción interna, o al sistema de provisión de puestos de trabajo o, en fin, a la disparidad de criterios en materia disciplinaria. Como se ha podido decir, "las disfunciones incorporadas en la D. A. $2^{a}$ EBEP habían acarreado una palpable desnaturalización del sistema de habilitación nacional” (DOMINGO ZABALLOS: 650).

En este sentido, no parece que las “excepciones" territoriales que contiene la reforma ayuden a clarificar adecuadamente el efectivo alcance de la competencia sobre la regulación de esta escala de funcionarios públicos. Me refiero, en concreto, a la persistente asimetría regulatoria en este punto: la "recentralización" sobre este "cuerpo nacional” no se aplica a la Comunidad Autónoma del País Vasco, que por medio de sus órganos forales mantiene con relación a estos funcionarios todas las competencias anteriores a la reforma (D. A. $\left.1^{\mathrm{a}} \mathrm{LRSAL}\right)$.

Así, en materia de selección, el Estado recupera la plenitud de funciones, correspondiendo al Ministerio de Hacienda y Administraciones Públicas, conforme a las bases y programas aprobados reglamentariamente, la aprobación de la oferta de empleo público y la selección, formación y habilitación de estos funcionarios (art. 92 bis. 5 LRBRL) ${ }^{20}$. Desaparece, pues, la posibilidad -habilitada por el EBEP- de que las Comunidades Autónomas puedan incorporar materias sectoriales de los ordenamientos correspondientes dentro de los programas. En uso de estas atribuciones, por medio del RD-Ley 5/2014, de 4 de abril, por el que se prevé una oferta de empleo público extraordinaria y adicional para el impulso de la lucha contra el fraude fiscal, se ha ampliado la oferta en la Escala de

19 Como se ha dicho, "debiera haberse previsto, para no instalar a la Secretaría en una posición de permanente pérdida de peso e influencia en la vida administrativa local, por no decir ignorancia y desprecio de su labor, como hasta ahora ocurre, dotarla de las facultades e instrumentos precisos para hacer posible la total observancia de la legalidad vigente, y no que esta sea objeto de permanente y regular incumplimiento. Los secretarios tendrían que estar facultados para emitir informe especial -art. 3.b) RJFHN-, sino también en aquellos otros que, a su juicio, infrinjan la legalidad vigente, dotándose al tiempo a los mismos de facultades para remitir a la Administración del Estado y Autonómica, junto con los acuerdos y resoluciones adoptadas, copia de los informes emitidos donde se recojan las infracciones cometidas", CEBRIÁN ABELLÁN (2014: 804).

20 De hecho, se encuentran ya disponibles en la Sede electrónica del INAP (https://sede.inap.gob.es/habilitados-nacionales), a la espera de la convocatoria correspondiente a 2014, las propuestas de temarios relativos a las distintas subescalas (Intervención-Tesorería categoría de entrada; Secretaría categoría de entrada y Secretaría-Intervención). A favor de la recuperación estatal de las facultades de selección de los funcionarios locales con habilitación de carácter nacional se pronuncia claramente por ejemplo DOMINGO ZABALLOS (2014: 666), entendiendo además que la nueva normativa básica estatal incorporada por la LRSAL ha desplazado y dejado sin efectos pro futuro la normativa autonómica que sea incompatible con ella, tanto de naturaleza reglamentaria como de rango legal. 
funcionarios locales con habilitación de carácter nacional al margen de la tasa común de reposición (en 210 plazas más, incluidas dentro de la categoría de vacantes puras, más la oferta de plazas de promoción interna), dado que las plazas vacantes reservadas a la misma no se pueden suprimir ni amortizar al tener carácter estructural en las Corporaciones locales y estar dotadas presupuestariamente con carácter necesario (se estima que un $35 \%$ de las plazas reservadas se encuentra vacante). Sus funciones, se añade, son cada día más importantes en la lucha contra el fraude, el control del déficit público y la consecución de la estabilidad presupuestaria, lo que exige una capacidad efectiva de respuesta por parte de las entidades locales.

No se introducen cambios significativos en relación a la estructura y categorías de las diferentes subescalas, remitiendo a una posterior norma reglamentaria (hasta ahora competencia autonómica) la ordenación de las especialidades de la creación, clasificación y supresión de puestos reservados a funcionarios de administración local con habilitación de carácter nacional, así como las que puedan corresponder a su régimen disciplinario y de situaciones administrativas (art. 92 bis. 2 a 4 LRBRL).

Igualmente se establece un reenvío-reserva reglamentaria al gobierno estatal para la regulación de las especialidades correspondientes de la forma de provisión de puestos reservados a esta escala de funcionarios, declarándose que el concurso, de ámbito necesariamente estatal, será el sistema normal de provisión (de nuevo aquí se cambia el ámbito territorial, de escala autonómica en la regulación originaria del EBEP, y, quizás más importante, se asegura la posibilidad/control de la determinación estatal de las "especialidades" de los procedimientos de provisión, lo cual, tanto desde el punto de vista de la subrepticia deslegalización procedimental como de la indefinición material de las mismas, no aporta mucha seguridad jurídica a la cuestión). Los méritos generales, de preceptiva valoración, se determinarán igualmente por la Administración del Estado y su puntuación alcanzará un mínimo del $80 \%$ (65\% en la regulación anterior) del total posible conforme al baremo correspondiente. A su vez, los méritos referentes a las especialidades de cada Comunidad Autónoma se fijarán por cada una de ellas, y su puntuación podrá alcanzar hasta un 15\% como máximo del total posible (anteriormente del 10\%), mientras que, finalmente, los méritos correspondientes a las singularidades de la Corporación local respectiva, que fijará ésta, podrán alcanzar hasta un $5 \%$ (frente al $25 \%$ anterior), del total posible. La variación de porcentajes, como puede verse, es significativa, sobre todo en la reducción del margen de maniobra de los propios entes locales, aparte del expreso desapoderamiento autonómico para la libre determinación del porcentaje de puntuación correspondiente a cada uno de estos méritos, reconocido por el EBEP. Pero quizás sea más discutible aún la propia ausencia en la Ley del contenido material, aún básico, de dichos méritos generales, lo cual queda remitido, una vez más, al desarrollo reglamentario -y, con ello, a la mayor predeterminación gubernamental sobre su alcance-. Por lo demás, seguirán existiendo dos concursos anuales: el ordinario y el unitario. El unitario, que no sufre grandes modificaciones (aunque aparentemente se pierde su carácter supletorio según el EBEP), será convocado por el Estado, mientras que las Corporaciones locales con puestos vacantes aprobarán las bases del concurso ordinario, aún en el marco y con respeto al modelo de convocatoria y bases que se aprueben también reglamentariamente (en el EBEP, estas bases eran de aprobación por las Comunidades Autónomas también) y las posteriores convocatorias²1.

Sí se reconoce a las Comunidades Autónomas, en el marco de la propia normativa estatal, el nombramiento provisional de estos funcionarios, así como las competencias de otorgamiento de las comisiones de servicios, acumulaciones, nombramientos de personal interino y de persona accidental, competencias todas ellas de clara naturaleza ejecutiva.

Como novedad, se establece ahora que los funcionarios deberán permanecer en cada puesto de trabajo, obtenido por concurso, un mínimo de dos años para poder participar en los subsiguientes concursos de provisión de puestos de trabajo o ser nombrados con carácter provisional en otro puesto de trabajo o destino, salvo en el ámbito de una misma entidad local (art. 92 bis.8 LRBRL), aunque excepcionalmente, y antes del cumplimiento de dicho plazo, se podrán hacer nombramientos provisionales por el Ministerio de Hacienda y Administraciones Públicas siempre que existan razones y circunstancias -que no parece que sean lo mismo, y que no se concretan en ninguno de los casos- para la cobertura con carácter urgente de un puesto reservado a esta Escala de funcionarios, sin que exista la posibilidad de efectuar un nombramiento provisional ordinario.

Finalmente, y a salvo de la cuestión de los nombramientos por libre designación, que comentamos después, sí ha sido objeto de profunda modificación el régimen disciplinario de estos funcionarios de habilitación nacional. La LRSAL modifica tanto la regulación previamente contenida en el EBEP (que había conllevado en la práctica una

$21 \quad$ Nada se dice en la LRSAL sobre la resolución de los concursos ordinarios. El EBEP indicaba que la misma correspondía a las Corporaciones locales, con remisión posterior a la Comunidad Autónoma para su publicación en su Diario oficial. Parece lógico entender, dada la filosofía de reforma, que si las convocatorias son realizadas por las entidades locales, su resolución corresponda a las mismas, publicándose a través de los mismos medios, y con el mismo alcance, que la convocatoria, aunque curiosamente tampoco en este caso la LRSAL menciona expresamente la necesidad de su publicación oficial en el BOE, como explica con claridad FONDEVILA ANTOLIN, J. (2014: 489-490). 
disparidad de órdenes regulatorios) como la vigente en el ámbito local con anterioridad a su entrada en vigor. Fundamentalmente, se realiza una clara distinción del alcance del ámbito competencial de las diferentes escalas de gobierno territorial, tanto para acordar la incoación de los expedientes disciplinarios como para la resolución de los mismos, desde la premisa garantista de la separación orgánica -e incluso institucional- de fases y del propósito de reforzamiento de la independencia y neutralidad de este cuerpo de funcionarios.

Así, serán órganos competentes para la incoación de los expedientes:

- En el caso de faltas leves, el órgano correspondiente de la Corporación local donde el funcionario hubiere cometido los hechos imputados;

- La Comunidad Autónoma respecto a funcionarios de corporaciones locales en su ámbito territorial, salvo que los hechos denunciados pudieran ser constitutivos de faltas muy graves tipificadas en la normativa básica estatal; y

- El Ministerio de Hacienda y Administraciones Públicas cuando los hechos denunciados pudieran ser constitutivos de faltas muy graves según la normativa básica estatal.

El órgano competente para acordar la incoación del expediente lo será también para nombrar instructor del mismo (necesariamente funcionario de carrera de cualquier Cuerpo o Escala del Subgrupo profesional A1 de titulación, con conocimientos además -y como acertada medida- en la materia sobre la que verse la infracción) y decretar o alzar la suspensión provisional del funcionario expedientado, así como para instruir, en su caso, diligencias previas.

Por su parte, serán órganos competentes para la imposición de las sanciones disciplinarias correspondientes:

- El Ministro de Hacienda y Administraciones Públicas, cuando la sanción que recaiga sea por falta muy grave contenida en la legislación básica estatal;

- El órgano autonómico correspondiente, en el caso de sanciones de suspensión de funciones y destitución, no correspondientes a tipos básicos estatales; y

- El órgano local competente, cuando se trate de imponer sanciones por faltas leves.

La sanción impuesta se ejecutará en sus propios términos, pero además se aclara que no será impedimento para ello el que el funcionario hubiera cambiado de destino, ocupando un puesto distinto -en otra Corporación- a aquel en que se produjeron los hechos que habían dado lugar a la sanción, lo que viene a resolver un problema práctico específico que se había planteado.

De esta nueva sistemática parecen desprenderse dos dudas interpretativas inmediatas. Una, sobre el órgano competente para la imposición de infracciones por faltas graves en general, que no se designa al menos expresamente; y otra, "imaginar" qué tipo de infracciones no muy graves pueden dar lugar, en su caso, a la destitución -término extraño por lo demás en nuestro sistema de empleo público, pero que la LRSAL hace equivaler a la pérdida del puesto de trabajo, con la prohibición de obtener destino en la misma Corporación en la que tuvo lugar la infracción-, para no dejar vacía de contenido, por tanto, la competencia sancionadora reservada a las Comunidades Autónomas.

Posiblemente la cuestión más espinosa -y criticable- de la nueva regulación de los funcionarios de habilitación nacional sea el mantenimiento, e incluso la extensión, de la posibilidad de utilización para la provisión de plazas vacantes del -ya por sí cuestionable- sistema de libre designación ${ }^{22}$.

Tras establecerse en el art. 92 bis. 6 LRBRL que la forma normal de provisión de puestos reservados a esta Escala será el concurso, de ámbito estatal además, a continuación se permite que, excepcionalmente, pueda utilizarse el sistema de libre designación: i) en los municipios incluidos en el ámbito subjetivo definido en los arts. 111 y 135 del TRLHL; ii) en las Diputaciones Provinciales, Áreas Metropolitanas, Cabildos y Consejos Insulares; y iii) en las ciudades con estatuto de autonomía (Ceuta y Melilla), designación que habrá que hacer, lógicamente, "entre funcionarios de la subescala y categoría correspondiente". Como garantía adicional, en el caso de puestos de trabajo que tengan asignadas las funciones de Intervención-tesorería, será necesaria la autorización expresa del órgano correspondiente de la Administración General del Estado (autorización, ¿para poder utilizar el sistema de libre designación?, dada la especial trascendencia de estas funciones de control, o ¿para poder nombrar por libre

22 Una fundada crítica puede verse, por ejemplo, en SERRANO PASCUAL (2014: 599 y ss.): “Hay que reafirmarse en la crítica a un modelo politizado de función pública ad nauseam, que no resiste la más mínima justificación intelectual y que muestra que lo que inicialmente se trató de vender como una medida excepcional se ha ido generalizando". 
designación a una persona en concreto?). A pesar de esta posible garantía, y del adverbio de "excepcionalidad" que encabeza el apartado correspondiente, lo cierto es que la pervivencia y ampliación del sistema de libre designación para la provisión de puestos de habilitación nacional compromete, por entero, las posibles bondades enlazadas a la reforma, fundamentalmente las relativas al pretendido incremento de la objetividad, imparcialidad y transparencia de sus actuaciones.

Efectivamente, la libre designación es -y ha sido- el portón abierto a la politización -y en consecuencia, a la falta de objetividad- de los funcionarios públicos ${ }^{23}$. Resulta cuestionable por ello que una reforma que, al menos, pretende reforzar y garantizar la profesionalidad y eficacia de las funciones de control interno -aunque sea para garantizar el principio clave de sostenibilidad presupuestaria-, mantenga, en términos de absoluta discrecionalidad, un sistema de acceso claramente incompatible con los principios de mérito y capacidad, en puestos clave, además, desde el punto de vista de la neutralidad funcional de dicho control. Evidentemente no parece la mejor opción para recuperar la confianza en las instituciones (y en los encargados, de hecho, de velar por su legalidad) y superar la propia crisis actual del principio de legitimidad democrática. Y menos en el mundo local, donde la enmascarada "confianza política" propia de las Administraciones superiores y sus Gobiernos se diluye, necesaria y afortunadamente, en pluralismo democrático de los órganos de gobierno. Como se ha dicho, "este procedimiento no puede dar cumplimiento a las exigencias de imparcialidad y objetividad en el hacer del funcionario público, ante la permanente espada de Damocles del cese discrecional cuando no arbitrario, a lo que se añade que el mismo no garantiza la exigencia constitucional de un funcionamiento eficaz de la Administración pública"24.

Hay que tener en cuenta además que, de acuerdo con la inversión del esquema de prelación de fuentes antes reseñado, las nuevas previsiones de la LRBRL prevalecerían sobre las -también escuetas- determinaciones específicas del EBEP en este punto (y desplazarían, además, la posible regulación autonómica en su desarrollo incompatible con ellas). El art. 80 EBEP establecía, al menos, que la libre designación de personal funcionario de carrera habría de hacerse con "convocatoria pública”, lo cual ha de seguir sobreentendiéndose a pesar del sorprendente silencio específico en este punto de la nueva redacción del art. 92 bis.6 LRBRL. Se dice, además, que el sistema consiste en la apreciación, discrecional pero no arbitraria (lo que demanda necesariamente una motivación suficiente en la decisión y de lo que se deriva, a la vez, la inherente existencia de ciertos elementos reglados susceptibles de control), de la "idoneidad" de los candidatos, en relación además con los requisitos exigidos para el desempeño del puesto a proveer. No es, pues, una mera relación fiduciaria de estricta y mínima confianza política. Dentro de la ambigüedad propia del EBEP, este sistema se configura como una posibilidad -ciertamente de riesgo- de nombramiento discrecional de acuerdo con parámetros subjetivos y funcionales de adecuación. Aún así, es evidente que la pervivencia en el EBEP de esta institución resulta difícilmente compatible con los principios constitucionales informantes de nuestro sistema de empleo público, y con las propias exigencias de profesionalidad, imparcialidad y neutralidad política de los funcionarios de carrera, tanto en el acceso al empleo público como en la provisión/ocupación de plazas vacantes (el apartado segundo de este art. 80 EBEP remitía por lo demás a las leyes de desarrollo el establecimiento de los "criterios" para la determinación de los puestos que por su especial responsabilidad y confianza podrían cubrirse mediante libre designación, con lo que a la discrecionalidad política se unía, también, la discrecionalidad organizativa -estatal y autonómica-).

Pues bien, ninguna de estas "garantías" mínimas aparece ahora reflejada en el caso de los funcionarios locales de habilitación de carácter nacional, lo que resulta chocante dada la especial trascendencia de sus funciones de control y asesoramiento interno, difícilmente compatibles con una pura relación de confianza política.

Cabría interpretar, no obstante, que el art. 92 bis.6 LRBRL no configura "un" sistema especial de provisión por libre designación para esta escala nacional, sino que permite su utilización, de forma excepcional, por el "mismo", en su configuración básica -y también difícilmente operativa- del EBEP. Esta segunda interpretación es, obviamente, menos discutible, pero chocaría con: i) la propia ampliación del ámbito institucional de aplicación de este sistema de provisión para esta escala de funcionarios, cuya "responsabilidad parece disminuir curiosamente según aumenta el tamaño del municipio" (FONDEVILA ANTOLíN: 505) y ii) la modificación, más restrictiva, de las condiciones profesionales y retributivas de los funcionarios cesados en el nuevo texto de la LRBRL.

Efectivamente, hasta ahora las entidades locales que podían utilizar el instrumento de la libre designación eran las autorizadas por las previsiones de la D. A. $2^{\text {a }}$ EBEP, modificado parcialmente a su vez por el art. 15 del RDLey 8/2010, de 20 de mayo, por el que se adoptan medidas extraordinarias para la reducción del déficit público, es decir, los municipios de gran población del art. 121 LRBRL (municipios con población superior a 250.000 habitantes; capitales de provincia cuya población sea superior a los 175.000 habitantes; capitales de provincia, capitales

23 Como se ha dicho, el sistema de libre designación (y libre cese) comporta normalmente riesgos vinculados a la pérdida de independencia y a la relajación de los controles, FUEYO BROS (2014: 412).

24 MOREY JUAN (2004: 72). 
autonómicas o sedes de instituciones autonómicas; y municipios con más de 75.000 habitantes con circunstancias económicas, sociales, históricas o culturales especiales) más las Diputaciones Provinciales, Cabildos y Consejos Insulares. Ahora, la LRSAL remite al art. 111 TRLHL (y al art. 135 TRLHL, referido, también con cierta desconexión temática, a la cesión de impuestos del Estado a las provincias), que considera incluidos dentro de su ámbito de aplicación a los municipios:

Que sean capitales de provincia o de Comunidad Autónoma; o

Que tengan población de derecho igual o superior a 75.000 habitantes.

Por tanto, a partir de ahora, cualquier municipio con más de 75.000 habitantes, sin necesidad de que concurran las especiales circunstancias enumeradas en el EBEP, podrá usar el sistema de libre designación para la provisión de puestos de trabajo reservados a funcionarios de habilitación nacional. Y parece evidente que el estancamiento del sistema en los años de "iniciativa autonómica" no puede solventarse con una flexibilización "política" de su sistema de nombramiento como la ahora adoptada. Las exigencias de "excepcionalidad" se diluyen en un sistema de reenvío abierto a la posibilidad de utilización -y posible instrumentalización, por ausencia de reglas mínimas de control- de esta figura, en más municipios que antes de la reforma incluso.

Pero es que además, la LRSAL introduce una nueva novedad para los casos de cese de estos funcionarios, que lógicamente es, como el nombramiento, discrecional: “La Corporación local deberá asignar entonces al funcionario cesado un puesto de trabajo de su mismo grupo de Titulación" (art. 92 bis. 6 in fine LRBRL). Se ha interpretado que dado que el EBEP no contenía ninguna previsión específica sobre este aspecto, se mantendría en vigor el cuerpo normativo reglamentario previo (concretamente, el RD 1732/1994, de 29 de julio, sobre provisión de puestos de trabajo reservados a funcionarios de Administración local con habilitación de carácter nacional, en su modificación por el posterior RD 834/2003, de 27 de junio), que preveía la garantía, en caso de cese discrecional, de la reubicación en un puesto de trabajo de su subescala y categoría en la Corporación local correspondiente, con remuneración no inferior en más de dos niveles a la del puesto para el que había sido designado, y, lo más importante, "clasificado como reservado a habilitados de carácter nacional, y con funciones de colaboración, apoyo y asistencia jurídica o económica" (FONDEVILA ANTOLÍN: 509). Pues bien, con la LRSAL desaparece dicha "reserva", lo cual puede afectar lógicamente a los caracteres de neutralidad e independencia propias de las funciones de control de este cuerpo especial de funcionarios de carrera ${ }^{25}$. Ahora, resultará posible adscribir al funcionario habilitado de carácter estatal tras el cese a cualquier puesto de trabajo de la RPT municipal, con tal de que se requiera únicamente para su cobertura la pertenencia al grupo A1 (y sin límite, además, de asignación de niveles), con independencia de las funciones a desarrollar (lo que carece de sentido) y con consecuencias perniciosas no sólo retributivas sino de implementación de posible "prácticas" revanchistas ${ }^{26}$.

Hay que tener en cuenta, finalmente, que, como se ha adelantado para la resolución óptima de alguno de los problemas interpretativos derivados de la nueva regulación de esta escala, la D. T. $7^{\text {a }}$ LRSAL mantiene expresamente la vigencia de la normativa reglamentaria (previa) referida a estos funcionarios, en tanto no se oponga a la nueva ordenación básica de la LRBRL, hasta la entrada en vigor del nuevo Reglamento de desarrollo previsto -y en muchos puntos necesario- por el art. 92 bis LRBRL ${ }^{27}$.

\section{CONTROL ECONÓMICO-FINANCIERO DE LA ACTIVIDAD LOCAL Y FORTALECIMIENTO DE LAS FUNCIONES DE INTERVENCIÓN}

Según su Preámbulo, uno de los objetivos de la LRSAL es mejorar el control económico-financiero de la Administración local, lo que pretende conseguirse, entre otras medidas, garantizando un control financiero y presupuestario más riguroso a través del reforzamiento de la función interventora en las entidades locales ${ }^{28}$.

Las garantías de sostenibilidad, equilibrio económico-financiero y eficiencia de la acción pública local son presupuesto, evidentemente, de una adecuada organización interna y, después, de una racional articulación de los medios, fines e instrumentos de intervención pública, a través de medidas de gestión directa o de mecanismos

25 Vide en este sentido las consideraciones de CANTERO MARTíNEZ (2014: 647).

26 Muy crítico con estas nuevas previsiones se muestra, por ejemplo, FONDEVILA ANTOLÍN (2014: 511 y ss.).

27 Ello ha permitido, en este período transitorio, y hasta la aprobación del necesario desarrollo reglamentario, la continuación de los concursos de provisión de puestos de trabajo vacantes en las Corporaciones locales reservados a estos funcionarios (por ejemplo, la Resolución de 7 de mayo de 2014, del Director General de Administración local y Relaciones Institucionales de la Consejería de Presidencia y Empleo de la Región de Murcia), así como la adopción autonómica de nuevas resoluciones de creación, clasificación y supresión de puestos de trabajo reservados a esta Escala, aunque publicadas ya de forma conjunta a nivel estatal (por ejemplo, la última Resolución de 3 de septiembre de 2014 de la Dirección General de la Función Pública, en la página específica del INAP sobre los mismos, http://seap.minhap.gob.es/es/areas/ funcion_publica).

28 Sobre las consecuencias y efectos de la aplicación del principio de estabilidad presupuestaria a las entidades locales puede verse, por ejemplo, GARCÍA-ANDRADE GÓMEZ (2012: 293 y ss.). 
de ordenación indirecta de los intereses generales. Pero, como se ha denunciado desde la publicación de la Ley, el paradigma "economicista" no puede ser exclusivo. Ni los grandes problemas de gasto público, déficit y descompensación presupuestaria provienen o son motivados por el ámbito local, mucho menos en un país plagado de pequeños municipios, ni cabe entender que la "modernización" de la Administración local puede pasar sólo por una mayor intervención y control del gasto público y de los mecanismos de financiación. Los problemas estructurales, y sobre todo aquellos que responden a una pluralidad de causas interconectadas (inadecuación quizás de la planta municipal, asunción irresponsable de competencias impropias, falta de mecanismos de coordinación competencial para evitar duplicidades y solapamientos de actuación, etc.), demandan respuestas también estructurales, es decir, ponderadas, programáticas y consensuadas ${ }^{29}$. La LRSAL, evidentemente, no da solución a estas cuestiones. Y a un año de su entrada en vigor, es posible, y así se ha constatado, que se haya conseguido una reducción del gasto público y una consolidación de las balanzas presupuestarias -en muchos municipios $-^{30}$, pero es evidente que ni se ha empezado a trabajar en la "racionalización" y "sostenibilidad" de la organización y funcionamiento, a escala transversal, del nivel local de gobierno.

Junto con la ya comentada recuperación estatal de los procesos de selección, formación y habilitación de los Funcionarios con Habilitación de carácter nacional, y la potestad sancionadora en los casos de infracciones muy graves, la potenciación del control económico-financiero de la Administración local ha pretendido conseguirse mediante la fijación por el Gobierno estatal de las normas sobre los procedimientos de control, metodología de aplicación y criterios de actuación, así como los derechos y deberes en el desarrollo de tales funciones interventoras, estableciéndose, así, una cierta homogeneización de esta actividad de control (y se supone que una mayor imparcialidad en su ejercicio). Pero realmente se ha cuestionado si esto (en definitiva, la ampliación del propio ámbito objetivo de los destinatarios de los informes de Intervención) va a suponer, de verdad, un "reforzamiento funcional" (cualitativo) de las tareas de intervención o, más sencillamente, un incremento cuantitativo de sus funciones, paralelo al propio incremento del control superior estatal de la actividad económica de los entes locales, con lo que la -pretendida- "independencia” orgánica local se diluiría, en el fondo, en la mayor "dependencia" funcional central en el desarrollo de su labor.

Según el nuevo art. 213 TRLHL, estas funciones de control interno habrán de ejercerse respecto de la propia gestión económica de la entidad, así como de los organismos autónomos y sociedades mercantiles de ella dependientes, tanto en sus modalidades de función interventora, como de control financiero, auditoría de cuentas y control de la eficacia. Se intenta, pues, extender al máximo el ámbito -subjetivo y objetivo- de control y fiscalización económico-presupuestaria de la actividad local. Para ello, el Ministerio de Hacienda y Administraciones Públicas establecerá las normas uniformes antes reseñadas.

El control superior se asegura, además, estableciendo la obligación de que los órganos de intervención local remitan anualmente a la Intervención General de la Administración del Estado un informe-resumen de los resultados de los controles desarrollados en cada ejercicio.

Parece clara, por tanto, la opción del legislador estatal por alejar del ámbito de decisión local la gestión del personal funcionario con funciones de control interno, a fin de garantizar -se pretende- la máxima independencia y autonomía en el control de legalidad y financiero de los procesos de actuación y de hacienda locales. En este sentido, las funciones del Interventor se amplían considerablemente ${ }^{31}$ :

- Emisión del informe previo sobre la sostenibilidad financiera de las propuestas planteadas para la elección de la fórmula concreta de gestión de los servicios públicos municipales (art. 85.2 LRBRL);

Elaboración para el punto especial del Pleno en el que se debe dar cuenta de todas las resoluciones adoptadas por el Presidente de la entidad contrarias a sus reparos, así como un resumen de las principales anomalías detectadas en materia de ingresos y remisión anual de un informe al Tribunal

29 Y es que hasta el propio legislador estatal es consciente de esta necesidad: como dice por ejemplo el Preámbulo de la reciente Ley 15/2014, de 16 de septiembre, de racionalización del Sector Público y otras medidas de reforma administrativa, "se debe asegurar que los servicios públicos se prestan de la forma más eficiente y al menor coste posible; que se aprovechan todas las economías de escala, que no se producen solapamientos ni duplicidades y que los procedimientos son simples y estandarizados" (lástima que luego, en su articulado, no se aborde una auténtica e integral reforma del sector público, sino medidas en su mayor parte de naturaleza específica y singular fundamentalmente de reorganización y simplificación del mismo, y orientadas fundamentalmente, de nuevo, a incrementar la eficacia y el ahorro del gasto público). El propio Consejo de Estado en su Dictamen al Anteproyecto de la misma había destacado, en primer lugar, una falta de correspondencia entre el título de la norma y su contenido, así como una cierta descompensación entre la extensión de la Exposición de Motivos y la concisión del articulado (MORENO SERRANO: 2014).

30 Ya a la mitad del año 2014, y según datos del Ministerio de Hacienda y Administraciones Públicas, se constataba que el gasto municipal agregado había ido disminuyendo casi un 10\% cada año en el último período analizado, pasando de 56.000 millones de euros a 50.000 en 2011 y a 46.000 millones en 2012.

31 Puede consultarse un desarrollo más pormenorizado de estas nuevas funciones en CARDOSA ZURITA (2014). 
de Cuentas con todas las resoluciones y acuerdos adoptados por el Presidente y el Pleno contrarios a los reparos (art. $218 \mathrm{TRLHL})$;

- Elaboración de un informe anual de auditoría de las cuentas de los consorcios adscritos a su entidad (D. A. $20^{\mathrm{a}} .4$ LRJAP);

- $\quad$ Elaboración de un informe previo al Plan de saneamiento individualizado de las entidades del sector público con déficit de su entidad (D. A. $9^{\mathrm{a}} .2$ LRBRL);

- Elaboración del certificado correspondiente sobre cumplimiento de los objetivos de estabilidad presupuestaria, deuda pública y pago a proveedores en orden a la exención de las limitaciones referidas al número de personal eventual y cargos públicos en régimen de dedicación exclusiva (D. T. $10^{\mathrm{a}}$ LRSAL); y

- Posible colaboración con la Administración General del Estado para la realización de actuaciones de apoyo "técnico" a sus funciones propias (D. A. $7^{\text {a } ~ L R S A L) . ~}$

\section{EL PERSONAL DIRECTIVO DE LA ADMINISTRACIÓN LOCAL}

Según el nuevo art. 32 bis LRBRL, el nombramiento del personal directivo que, en su caso, hubiera en las Diputaciones, Cabildos y Consejos Insulares ${ }^{32}$ deberá efectuarse de acuerdo a criterios de competencia profesional y experiencia, entre funcionarios de carrera del Estado, de las Comunidades Autónomas, de las entidades locales o con habilitación de carácter nacional que pertenezcan a cuerpos y escalas clasificados en el Subgrupo A1, salvo que el correspondiente Reglamento Orgánico permita que, en atención a las características específicas de las funciones de tales órganos directivos, su titular no reúna dicha condición de funcionario (se subsana, así, la laguna derivada de la regulación introducida para este personal por la Ley 57/2003). También el nuevo art. 130.3 LRBRL efectúa una previsión similar respecto al nombramiento de los coordinadores generales y de los directores generales en los municipios de gran población. Respectivamente, las D. T. $6^{\mathrm{a}}$ y $7^{\mathrm{a}}$ LRSAL aclaran que estas nuevas limitaciones sólo serán de aplicación a los nombramientos posteriores a su entrada en vigor.

Aunque la primera parte del precepto pudiera hacer pensar en la intención del legislador de "profesionalizar" definitivamente, al menos en el ámbito local (y solamente a nivel provincial además), esta figura del personal directivo (o de la "función directiva"), o al menos aclarar en parte su difusa regulación estatutaria -en su indefinida positivización legal por el EBEP-, la segunda disipa -negativamente- tales dudas. Puede entenderse que el nombramiento del personal directivo no responda a las notas, sin embargo de carácter transversal e ineluctable en el EBEP, de mérito y capacidad (art. 13.2 EBEP), sino a criterios, más difusos, de "competencia profesional y experiencia", dada la naturaleza "peculiar" de sus funciones -en un estrato intermedio entre el nivel político y el nivel administrativo superior-, y las propias premisas de partida además de necesidad de su condición como funcionarios de carrera y de máxima clasificación profesional. Ahora bien, que un Reglamento Orgánico pueda excepcionar directamente lo previsto en una Ley no parece lo más "adecuado"desde la perspectiva de la confianza institucional y el aseguramiento de un mínimo de "profesionalidad y competencia" a los titulares de estas funciones de coordinación superior directiva. Aunque normativamente sea factible, una "autodeslegalización” para excepcionar -vía reglamentos internos- lo que en la Ley parece ser la regla general, puede suscitar dudas de legitimidad, control y transparencia33. Sobre todo porque la exención carece además de control, pues decir que se basará en las "características específicas de las funciones" es decir poco, o nada, en una nueva invocación tautológica para justificar umbrales obvios de discrecionalidad -aunque en este caso haya de hacerse mediante norma reglamentaria lógicamente aprobada y discutida en Pleno- en la toma de la decisión correspondiente. Por tanto, a mi juicio, la "vía de escape" abierta a través de la posibilidad de la exención de la condición de funcionario de carrera vía reglamentación organizativa local difumina cualquier posibilidad de avance hacia la "profesionalización” y “objetivización” estatutarias de este personal, aunque se haya avanzado algo en relación a la situación anterior (en donde sólo se exigía que la excepción fuera acordada por el Pleno). Aparentemente, pues, se han rebajado los requisitos en relación a la existencia de personal directivo tanto en los municipios de gran población como en las Diputaciones Provinciales. Finalmente, también habría que cohonestar esta nueva previsión de la LRBRL, de habilitación reglamentaria local para la determinación autónoma del -una

32 Hasta ahora, en la legislación de régimen local, el personal directivo estaba regulado básicamente en el art. 130 LRBRL, con referencia solamente a los municipios incluidos en el régimen de gran población.

33 En este sentido, y como se ha apuntado, dado que la excepcionalidad a la exigencia de la condición de funcionario de carrera tiene una redacción idéntica a la establecida para los Directores Generales de la Administración General del Estado (art. 18.2 LOFAGE), la jurisprudencia recaída sobre dicho precepto debería servir como criterio interpretativo en su traslación ahora al ámbito local: y dice, así, por ejemplo la STS de 3 de septiembre de 2010: "cualquier excepción que sea establecida a la regla general de reserva funcionarial exigirá, para poder ser considerada válida, que se apoye en hechos objetivos y concretos; y por dicha razón no bastaran consideraciones abstractas o genéricos juicios de valor" (DÍEZ QUESADA y GONZÁLEZ-HABA GUISADO: 2014). 
parte al menos- régimen jurídico del personal directivo, con la más restringida posibilidad prevista por ahora en el art. 13 EBEP, que sólo reconoce a los gobiernos -estatal y autonómicos- la capacidad para su determinación, en desarrollo de las escuetas determinaciones contenidas en dicho precepto (bien es verdad, no obstante, que tampoco el EBEP exige la condición de funcionario de carrera para el nombramiento como directivo, aunque sí, y eso no lo menciona el nuevo art. 32 bis LRBRL, que la selección se haga a través de procedimientos que garanticen la publicidad y la concurrencia competitivas) ${ }^{34}$.

Como se ha dicho de forma esquemática, si se trata de acabar con la politización del estrato directivo -al menos en el ámbito local-, la medida no puede ser criticada, pero es cierto que su visión y su propia dinámica son, ciertamente, muy limitadas, y de escaso recorrido, porque se evita la politización, pero no se consigue o no se prueba que los valores determinantes se asocien realmente a la cultura de dirección y que, más allá del criterio de reclutamiento, la permanencia y la actividad en la Administración estén presididas por valores diferenciales a los de la permanencia de los funcionarios públicos (PALOMAR OLMEDA: 758).

Por tanto, hay una clara apuesta por la "funcionarización" del directivo público provincial, pero no exactamente por su "profesionalización": las nuevas previsiones son muy modestas y ni siquiera se aproximan a los condicionantes mínimos pergeñados en el art. 13 EBEP, en tanto que en el nuevo régimen de los "directivos locales" no se encuentra ninguna alusión a las notas de responsabilidad y de evaluación y control de resultados, que deben ser inherentes a esta figura35.

A las dudas apuntadas, hay que añadir, como hemos apuntado, que los requisitos establecidos ahora con carácter específico en el nuevo art. 32 bis LRBRL, sólo serán exigibles a aquellos nombramientos que se realicen con posterioridad a la entrada en vigor de la reforma, sin afectar pues a los anteriores (D. T. $8^{\mathrm{a}} \mathrm{LRSAL}$ ).

La evidencia de que la función directiva no vaya a convertirse, de verdad, en una "dirección profesionalizada" es que la propia LRBRL sigue regulando, ahora con modificaciones, los denominados "contratos mercantiles o de alta dirección", que además no se limitan a los entes territoriales locales primarios o matrices, sino a los "entes, consorcios, sociedades, organismos y fundaciones que conforman el sector público local” (D. A. 12 ${ }^{\mathrm{a}}$ LRBRL, en la versión establecida por la D. A. $37^{\text {a }}$ LRSAL). La Disposición se limita no obstante, sin pronunciarse sobre el sistema de selección ni sobre el procedimiento para llevar a cabo la contratación, a regular la dimensión puramente económica de estos contratos, dividiendo las retribuciones en básicas (en función de las características de la entidad) y complementarias (complemento de puesto y complemento variable en función de las tareas o competencias asignadas al puesto de trabajo y a los objetivos previamente establecidos a alcanzar) ${ }^{36}$.

Sí se produce a continuación, no obstante, un intento de sistematización mínima de la estructura local a los efectos de la existencia o no de personal directivo. El Pleno de cada Corporación debe "clasificar" el conjunto de entes vinculados o dependientes de la entidad en tres grupos, según las siguientes características: volumen o cifra de negocios, número de trabajadores, necesidad o no de financiación pública, volumen de inversión y características del sector en que desarrolla su actividad. Los criterios clasificatorios son, en algún caso, algo vagos, pero resulta congruente desde la perspectiva de la racionalización organizativa local la ordenación del -en ocasiones desbordado- sector público instrumental correspondiente. Esta clasificación se tendrá en cuenta, además, para:

Establecer el número máximo de miembros del Consejo de Administración y de los órganos superiores de gobierno o administración de dichas entidades instrumentales; y

En lo que aquí interesa, para fijar el número mínimo y máximo de directivos así como la cuantía máxima de su retribución anual (donde se incluyen también las posibles “retribuciones en especie”), con determinación del porcentaje máximo del complemento de puesto y variable, cuantía total que, lógicamente, no podrá superar los límites fijados anualmente con carácter básico por la Ley de Presupuestos Generales del Estado.

34 Por todo ello se ha dicho que "la regulación de la LRSAL carece de sentido y es una muestra del sistema de confianza política en lugar de la apuesta por una función directiva profesional” (SERRANO PASCUAL: 607).

35 CANTERO MARTÍNEZ (2014: 669-670).

36 Acaba además la D. A. 12 $2^{\mathrm{a}}$ LRBRL con una regla de cierre evidente pero oportunamente reflejada ahora: "la extinción de los contratos mercantiles o de alta dirección no generará derecho alguno a integrarse en la estructura de la Administración local de la que dependa la entidad del sector público en la que se prestaban tales servicios, fuera de los sistemas ordinarios de acceso". No cabe pues, frente a prácticas fraudulentas que se han podido llevar a cabo, la "reasignación" o la "integración automática" en el empleo público al margen de los sistemas, más que "ordinarios", legales de acceso. De todas formas, esta regulación no puede desconocer, en ningún caso, el marco-superior, básico y específicovigente: la D. A. $1^{a}$ EBEP se aplica, en este sentido, a cualesquiera entidades del sector público estatal, autonómico y local en lo relativo, en lo que aquí interesa, a los principios rectores del acceso al empleo público, con difícil encaje de esta figura de los "contratos mercantiles" en este modelo, SERRANO PASCUAL (2014: 609). 
Ahora bien, mientras que a continuación la propia D. A. 12 $2^{\mathrm{a}}$ LRSAL concreta ya, en función del grupo clasificatorio de la entidad, los umbrales correspondientes en cuanto a los miembros de los Consejos de Administración y órganos superiores de gobierno o administración (15 miembros en las entidades del Grupo 1; 12 en las del Grupo 2; y 9 en las del Grupo 3), no se realiza tal operación en relación con el número máximo del personal directivo, con lo que la LRBRL deja en el aire, realmente, el número (máximo) posible de directivos que pueden existir en cada entidad instrumental local, en función de su clasificación organizativa.

\section{OTRAS PREVISIONES CON POSIBLES EFECTOS INDIRECTOS SOBRE EL EMPLEO PÚBLICO LOCAL}

Parece evidente, y la realidad lo ha demostrado en su primer año de vida, que la LRSAL es más una Ley de desarrollo de la LOEPSF que de "racionalización" estructural de las organizaciones locales. Los principios de estabilidad presupuestaria, reducción del déficit público y reequilibrio económico-financiero de las haciendas locales no son sólo la "inspiración" inmediata de la reforma, sino los mismos "criterios de ordenación" del grueso de las medidas puestas en marcha. En este sentido, el tratamiento del empleo público ha sido parcial (y de muchos otros aspectos de la organización, competencias y funcionamiento de las entidades locales), con la vista puesta fundamentalmente en el ahorro y la contención presupuestaria o en la potenciación de los mecanismos y de los responsables del control interno (tanto de legalidad como económico-presupuestario). Desde este punto de vista, los planes económico-financieros de las "entidades incumplidoras" recogidos en el art. 116 bis adquieren una especial relevancia. $Y$ dentro de las medidas que necesariamente han de incluirse en los mismos -aún posiblemente sin la cobertura internormativa necesaria- se encuentran las de "racionalización organizativa", que obviamente puede acarrear cambios sustanciales (aunque dentro de la indefinición de la Ley no se aclara el contenido de la misma) sobre el conjunto y el propio régimen jurídico estatutario de los empleados públicos afectados. Habrá que estar, lógicamente, al tipo e intensidad de "medida de racionalización" prevista en el "plan de saneamiento" aprobado, para atisbar la posible afección sobre el número, situación o características funcionales de los empleados de la entidad, en el marco, en cualquier caso, de las determinaciones básicas sobre movilidad, traslado o reasignación de efectivos contenidas en el EBEP, y con la lógica modulación del tipo específico de vínculo de empleo afectado (art. 81 y ss. EBEP) ${ }^{37}$. Todo ello, además, en un contexto de indefinición derivado del hecho de que, realmente, cualquier medida de reestructuración o remodelación de la organización o funcionamiento de la entidad "en problemas", ya se trate de supresión de competencias impropias, reconsideración de las fórmulas de gestión de los servicios, supresión de entidades inferiores o fusión de municipios colindantes, conllevará una clara afección -en mayor o menor medida, directa o indirectamente- sobre el "factor humano" de la Corporación o sus entes dependientes o vinculados. Es el caso, por ejemplo, de aquellas entidades instrumentales con funciones de naturaleza económica que a la entrada en vigor de la LRSAL tuvieran "desequilibrio financiero", que, en dos meses, debían aprobar, según la D. A. $9^{\text {a }}$ LRBRL, un "plan de corrección" del mismo. Si esta corrección no se cumple a 31 de diciembre de 2014, la entidad local, en un plazo máximo de 6 meses, debería disolver la entidad, lo que conllevaría, en el caso por ejemplo de funcionarios de carrera adscritos a la misma, la reubicación, reasignación o traslado de los mismos ${ }^{38}$.

Igualmente, la asunción por las Comunidades Autónomas de las competencias (de ejercicio local ahora) relativas a educación, salud y servicios sociales, a través del peculiar mecanismo de "condicionalización estatal" de "asunción estatutaria" de las mismas (D. A. $15^{\mathrm{a}}$ y DD. TT. $1^{\mathrm{a}}$ y $2^{\mathrm{a}} \mathrm{LRSAL}$ ) debería acarrear consecuencias importantes de reasignación o reubicación del personal público afectado. En relación por ejemplo a los funcionarios de carrera municipales, y dado que se trata de una cesión o asunción definitiva de la titularidad -y su posterior ejercicio- de dichas competencias, el traspaso genérico de medios económicos, materiales y personales previsto en la LRSAL tendrá que traducirse, lógicamente, en mecanismos de transferencia y de reconocimiento de la posterior situación de servicios en otras Administraciones Públicas reconocida en el art. 88 EBEP, aunque en el mismo no haya menciones expresas realmente a las consecuencias del traslado orgánico de funcionarios locales (en cuestiones clave como el grado personal a reconocer, el régimen de retribuciones correspondiente, etc. $)^{39}$.

37 En el caso del personal laboral, por ejemplo, y a falta de determinaciones específicas en el texto de la reforma, habrá que acudir, en los supuestos de reorganización competencial o de trasvase de competencias, a la técnica "subrogatoria" empresarial contenida genéricamente en el art. $44 \mathrm{ET}$, siempre que se den los requisitos para ello, lo establezca así el convenio colectivo o se determine en las previsiones adoptadas para la reestructuración del personal. En caso contrario, se podrá recurrir a una de estas tres posibilidades: bien al despido por las causas del art. 51 ET o del art. 52.c) ET; bien a la rescisión de los contratos por la vía que recoge el art. 49.1.g) ET, referida a la "extinción de la personalidad jurídica del contratante"; o bien, incluso, en solución menos aceptable, al despido por fuerza mayor, RODRícUEZ ESCANCIANO (2014: 580-581).

38 Puede tomarse como ejemplo para valorar la efectividad de esta medida uno de los primeros planes aprobados, el Plan de Reestructuración del Sector Público del Ayuntamiento de Madrid, que, sin embargo, y realmente, no predispone ni detalla exactamente el conjunto de medidas a adaptar en materia de empleo público, sino que reenvía a cada una de las empresas públicas municipales afectadas en su ordenación práctica, pero con lógicas previsiones en materia de reordenación y reajuste de plantillas en orden a equilibrar la nueva situación funcional resultante de la ejecución del plan con el nivel de empleo vinculado, vide Plan de Ajuste 2012-2022 (Revisión 2014), aprobado mediante Resolución de 13 de mayo de 2014 de la Secretaría General de Coordinación Autonómica Local del Ayuntamiento de Madrid.

39 Como se ha dicho, "pese a la magnitud de este proceso de transferencias de cometidos administrativos, en realidad son muy escasas 
Mucho más en el aire, en fin, se encuentran los efectos sobre el empleo público local de otras medidas atenuadas efectivamente en el texto final de la LRSAL- pero claves en el nuevo "entendimiento" estatal del papel de los entes locales en el ejercicio de sus "competencias propias", como la posibilidad de "coordinación superior provincial" para la prestación de los servicios obligatorios en los municipios con población inferior a 20.000 habitantes (art. 26.2 LRBRL), donde - es verdad con la "conformidad" ahora de los municipios afectados y de acuerdo con la decisión final del Ministerio de Hacienda y Administraciones Públicas- la Diputación puede proponer la implantación de fórmulas de gestión compartida a través de consorcios, mancomunidades u "otras fórmulas" (cláusula abierta donde las haya y que podría acoger cualquier propuesta, desde la posibilidad de cesión, traspaso o adscripción de empleados públicos municipales hasta las más intensas de externalización o privatización de los servicios, pasando por la delicada situación en la que se podrían encontrar fundamentalmente los empleados laborales afectados). $U$ otras previsiones de la reforma, como la posibilidad de suscripción de acuerdos intersubjetivos de delegación del ejercicio de las competencias (art. 27.1 LRBRL) o de mecanismos de colaboración interadministrativa (art. 57 LRBRL) ${ }^{40}$.

\section{BIBLIOGRAFÍA}

CANTERO MARTÍNEZ, Josefa (2014), Reforma local y función pública. El nuevo régimen de los funcionarios locales con habilitación de carácter nacional, en QUINTANA LÓPEZ, T. (dir.), La reforma del régimen local, Tirant lo Blanch, Valencia, págs. 645-713.

CARDOSA ZURITA, Carlos (2014), "El reforzamiento de la función interventora de los Secretarios-Interventores e Interventores en la Ley de Racionalización y Sostenibilidad de la Administración Local: novedades y actuaciones a desarrollar", El Consultor de los Ayuntamientos y de los Juzgados, nº 5, págs. 614-622.

CEBRIÁN ABELLÁN, Manuel (2014), El régimen local tras la reforma de la Ley de Racionalización y Sostenibilidad, Bosch, Barcelona.

DíEZ QUESADA, Agustín y GONZÁLEZ-HABA GUISADO, Vicente María (2014), “Innovaciones de la Ley de Racionalización y Sostenibilidad de la Administración Local en materia de empleo público y en el régimen retributivo de los miembros de las corporaciones", El Consultor de los Ayuntamientos y de los Juzgados, $n^{\circ}$ 2, Quincena del 30 de enero al 14 de febrero de 2014.

DOMINGO ZABALLOS, M. J. (2014), El empleo público local en la Ley de Racionalización y Sostenibilidad de la Administración Local (I): los funcionarios con habilitación de carácter nacional, en DOMINGO ZABALLOS, M. J. (coord.), Reforma del Régimen Local. La Ley de racionalización y Sostenibilidad de la Administración Local: veintitrés estudios, Thomson Reuters-Aranzadi, Pamplona.

FERNÁNDEZ RAMOS, Severiano (2013), “Los falsos empleados públicos: el personal eventual”, Revista General de Derecho Administrativo, $\mathrm{n}^{\circ} 34$.

FONDEVILA ANTOLÍN, Jorge (2014), La reforma y el empleo público local. Una caja de sorpresas, pero pocas buenas, en CARRILLO DONAIRE, J. A. y NAVARRO RODRíGUEZ, P. (coords.), La reforma del régimen jurídico de la Administración Local. El nuevo marco regulatorio a la luz de la Ley de Racionalización y Sostenibilidad de la Administración Local, La Ley-El Consultor de los Ayuntamientos, Madrid, págs. 427-579.

FORCADELL I ESTELLER, Xavier, Aproximación crítica a los principios cambios en la legislación de régimen local como consecuencia de la aprobación de la Ley 27/2013, de 27 de diciembre, de racionalización y sostenibilidad de la Administración Local, en SANTAMARÍA PASTOR, Juan Alfonso (2014), La reforma de 2013 del régimen local español, $2^{\mathrm{a}}$ ed., Fundación Democracia y Gobierno Local, Madrid.

FUEYO BROS, Manuel (2014), Fortalecimiento de la figura del Interventor. Función interventora y control interno: el control evanescido, en CARRILLO DONAIRE, J. A. y NAVARRO RODRÍGUEZ, P. (coords.), La reforma del régimen jurídico de la Administración Local. El nuevo marco regulatorio a la luz de la Ley de Racionalización y Sostenibilidad de la Administración Local, La Ley-El Consultor de los Ayuntamientos, Madrid, págs. 383-421.

las reglas específicas referidas a los traspasos de personal y las consecuencias que tendrán esas medidas sobre los recursos humanos. Los primeros borradores de la Ley de reforma sí establecían este tipo de previsiones, haciendo referencia expresa al régimen jurídico aplicable al personal afectado por los trasvases, pero la versión definitiva las ha omitido, generando lagunas de difícil solución", RODRíGUEZ ESCANCIANO, S. (2014: 570).

40 Como resumidamente se ha señalado, "la aplicación de la LRSAL deberá provocar procesos de transferencia de recursos humanos y de modificación en la prestación de servicios que harán necesario que las Administraciones pongan en marcha procesos de planificación en sus estructuras y servicios, con los objetivos e instrumentos que establece el art. 69 EBEP. Y el régimen jurídico de las medidas a adoptar dependerá de las necesidades a satisfacer y de la tipología a instrumentar (movilidad, reestructuración, redimensionamiento, etc.), así como de la clase de empleados públicos afectados (funcionarios de carrera, funcionarios interinos, laborales fijos, laborales indefinidos, laborales temporales, etc.), DÍEZ QUESADA y GONZÁLEZ-HABA GUISADO (2014). 


\section{GARCÍA-ANDRADE GÓMEZ, Jorge}

- La aplicación del principio constitucional de estabilidad presupuestaria a las entidades locales, en COSCULLUELA MONTANER, L. y MEDINA ALCOZ, L. (dirs.), Crisis económica y reforma del régimen local, Civitas, Madrid, 2012, págs. 293-325.

- Guía Práctica sobre la Ley de Racionalización y Sostenibilidad de la Administración Local (2014), Fundación Democracia y Gobierno Local, Madrid.

MORENO SERRANO, Beatriz (2014), "Comentario de urgencia a la Ley de Racionalización del Sector Público y otras medidas de reforma administrativas", El Consultor de los Ayuntamientos y de los Juzgados, n 19, 23 de septiembre de 2014.

MOREY JUAN, A. (2004), La Función Pública: necesidad de un análisis conceptual y de la revisión del sistema de libre designación, INAP, Madrid.

PALOMAR OLMEDA, A. (2014), La afección al régimen de personal y del empleo público, en DOMINGO ZABALLOS, M. J. (coord.), Reforma del Régimen Local. La Ley de racionalización y Sostenibilidad de la Administración Local: veintitrés estudios, Thomson Reuters-Aranzadi, Pamplona.

RODRÍGUEZ ESCANCIANO, Susana (2014), El personal laboral al servicio del sector público local tras la Ley 27/2013, de 27 de diciembre, de Racionalización y Sostenibilidad de la Administración Local, en QUINTANA LÓPEZ, Tomás (dir.), La reforma del régimen local, Tirant lo Blanch, Valencia, 2014, págs. 545-644.

SERRANO PASCUAL, Antonio (2014): "El empleo público en la Ley de Racionalización y Sostenibilidad de la Administración Local: claroscuros y falta de apuesta firme por la modernización y por un modelo funcionarial de lucha contra la corrupción", El Consultor de los Ayuntamientos y de los Juzgados, nº 5, págs. 590-611. 